\title{
Legitimidade democrática e apoio político: inovações recentes no debate internacional
}

\author{
Julian Borba ${ }^{1}$ (i) \\ Gabriela Ribeiro Cardoso ${ }^{2}$ (i)
}

\begin{abstract}
Os recentes fenômenos relacionados à denominada crise das democracias, como o populismo e a polarização política, têm colocado novos desafios à pesquisa sobre legitimidade e apoio político. Diante dos reconhecidos limites do modelo eastoniano, desde a década de 1990, vários autores têm proposto novas perspectivas analíticas aos estudos sobre o fenômeno. No presente artigo, apresentamos e analisamos, além da concepção original de David Easton, cinco perspectivas recentes que têm trazido inovações relevantes aos estudos sobre apoio político. Na parte final, são discutidos os avanços e os limites dessa literatura para a compreensão de alguns dilemas das democracias contemporâneas, especialmente o crescente apoio do eleitorado a candidatos e partidos com plataformas políticas autoritárias em vários países do mundo.
\end{abstract}

Palavras-chave: cultura política; legitimidade; apoio político; democracia

\section{Introdução}

Fenômenos políticos recentes como a vitória eleitoral de Donald Trump nos Estados Unidos e a ascensão eleitoral da nova direita na Europa fizeram com que o debate sobre a "crise da democracia" tenha chegado ao contexto dos países centrais. É como se a conjugação entre democracia liberal e capitalismo, que foi louvada como o "fim da história", estivesse assentada em bases muito frágeis. O debate em torno dessa temática tem extrapolado em muito os muros da academia, tendo produzido best-sellers internacionais: "Como as democracias morrem" (Levitsky e Ziblatt, 2018), "O povo contra a democracia" (Mounk, 2019) e "Como a democracia chega ao fim" (Runciman, 2018) são apenas três exemplos de uma onda "pop" da ciência política.

O que há em comum nessa literatura é o diagnóstico de que: (1) a democracia está em crise; (2) o risco de reversão autoritária é real (nas jovens e velhas democracias); e, o mais surpreendente, (3) tal reversão autoritária é amparada pela vontade do povo!

\footnotetext{
${ }^{1}$ Universidade Federal de Santa Catarina (UFSC), Departamento de Sociologia e Ciência Política. Florianópolis (SC), Brasil. E-mail: <borbajulian@yahoo.com.br>.

2 Universidade Federal de Santa Catarina (UFSC), Departamento de Sociologia e Ciência Política. Florianópolis (SC), Brasil. E-mail: <grcgabi@gmail.com>.
} 
O que causa surpresa nesse novo diagnóstico de crise é que o domínio institucionalista na ciência política havia criado um consenso de que a democracia construiria as condições de sua própria reprodução. Instituições democráticas, à medida que se reproduzissem ao longo do tempo, criariam as condições para o aprendizado de normas e valores democráticos pelos cidadãos (Dahlum e Knutsen, 2016). Não por acaso, a idade ininterrupta da democracia tem sido usada como um dos principais preditores de consolidação do regime (Svolik, 2014).

Mas se a democracia criaria sua própria demanda, como enquadrar o fenômeno da reversão autoritária descrito acima e que, segundo os mesmos autores, tem atingido tanto jovens quanto velhas democracias? Como explicar que cidadãos que vivem sob centenárias normas democráticas estejam possivelmente cada vez mais dispostos a abrir mão delas em troca de "crescimento econômico" ou "combate à corrupção", para ficar apenas em dois exemplos?

Isso nos leva a um tema clássico da ciência política que foi relegado a segundo plano pela literatura recente: como diferentes formas de organização política (ou sistemas políticos) obtêm apoio daqueles que são membros de uma comunidade política. Estamos aqui falando dos temas da legitimidade e da legitimação, que, desde a obra de Easton, são abordados analiticamente sob o conceito de apoio político. Para essa literatura, as condições de reprodução de um regime não estão dadas em sua natureza, como certa tradição institucionalista chegou a pensar. Trata-se aqui de tematizar o vínculo entre cidadãos eleitores e sistema político. Por exemplo, como se estabelece o compromisso com a aceitação das regras do jogo democrático? Para usar uma expressão de Przeworski (1994), como o compromisso com a "incerteza dos resultados" se estabelece? Como se renova? E, por fim, como ele é quebrado?

Neste artigo, pretendemos avançar, mesmo que indiretamente, em torno dessas questões, fazendo um balanço de alguns desenvolvimentos recentes na literatura internacional sobre legitimidade e apoio político. Nossa tarefa é facilitada pela existência de iniciativa anterior que sistematizou parte do debate (Magalhães, 2018). De modo a não sermos repetitivos, vamos tentar avançar em aspectos não diretamente abordados no referido estudo, especialmente os seguintes: 1) as relações entre os conceitos de legitimidade e apoio político em David Easton; 2) as diferentes concepções de legitimidade democrática que emergiram nas duas últimas décadas. Além disso, buscaremos problematizar criticamente as contribuições e limites das pesquisas sobre legitimidade e apoio político para o diagnóstico das democracias contemporâneas.

Não é nossa intenção fazer uma análise exegética das diferentes abordagens. A leitura será orientada analiticamente por duas questões: 1) a concepção analítica e metodológica de cada abordagem; 2) como mobilizam seu enquadramento conceitual e metodológico para analisar fenômenos empíricos concretos e qual o diagnóstico do fenômeno empírico analisado.

Antes de entrar na análise das diferentes abordagens, cabem alguns esclarecimentos sobre o escopo de tal revisão e os critérios de inclusão/exclusão. Nossa 
seleção dos textos seguiu uma abordagem intencional, de modo que utilizamos como critério de inclusão a representatividade e o reconhecimento dos referidos autores/textos no debate recente da área de comportamento político, utilizando para tanto a delimitação de tal campo estabelecida em estudos recentes (Dalton e Klingemann, 2007; Fisher, 2018).

Uma segunda delimitação que se faz necessária é quanto à distinção entre legitimidade democrática e satisfação com a democracia. Apesar de muitos autores usarem as duas dimensões como indicadores de "apoio" ao regime (Foa e Mounk, 2016; Mounk, 2019; Shore, 2019), trata-se de fenômenos analiticamente distintos, sendo o segundo "highly contaminated by incumbent support" (Torcal e Moncagatta, 2011, p. 4). Por essa razão, não abordaremos aqui os estudos sobre satisfação com a democracia.

O artigo está organizado em três partes, além desta introdução. Na primeira, "Legitimidade e apoio político: o modelo eastoniano", apresentamos o pioneiro modelo de David Easton. Já a segunda parte, "Inovações na literatura sobre legitimidade e apoio político pós-1990", trata das inovações na literatura sobre legitimidade e apoio político, após 1990. Na parte final, "Legitimidade, apoio político e as democracias contemporâneas: considerações finais", indicamos alguns avanços e limites do referido subcampo de pesquisa e fazemos alguns apontamentos sobre seus desafios analíticos e empíricos.

\section{Legitimidade e apoio político: o modelo eastoniano}

Em 1965, David Easton publicou a obra A systems analysis of political life, que se tornou uma referência importante para o debate empírico sobre legitimidade democrática. A distinção ali realizada entre apoio difuso e apoio específico tornou-se central para compreender a avaliação dos regimes democráticos e embasou tanto estudos de caso quanto trabalhos comparativos.

No contexto da análise do sistema político e do apoio em relação aos objetos políticos, Easton (1965) distingue entre modos (apoio difuso e apoio específico) e objetos do apoio (comunidade política, regime político e autoridades políticas), conforme explicitado na Tabela 1 . O autor tende a restringir o apoio específico às autoridades políticas, enquanto o apoio difuso está relacionado a todos os objetos do apoio. $\mathrm{O}$ apoio específico é definido como uma avaliação da política cotidiana e pode mudar rapidamente, enquanto o apoio difuso é definido de modo menos claro e, dependendo do objeto, possui diferentes subdimensões que assumem distintas formas (Westle, 2007). Logo, o apoio específico seria direcionado às decisões, políticas, declarações ou estilo das autoridades ${ }^{3}$.

\footnotetext{
3 "It is directed to the perceived decisions, policies, actions, utterances or the general style of these
} authorities" (Easton, 1965, p. 437). 
Tabela 1

Apoio político segundo Easton

\begin{tabular}{|l|c|c|c|}
\hline Modos de apoio & \multicolumn{3}{|c|}{ Objetos do apoio } \\
\hline Difuso & Comunidade política & Regime político & Autoridade políticas \\
\hline Específico & $\mathrm{X}$ & $\mathrm{X}$ & $\mathrm{X}$ \\
\hline
\end{tabular}

Fonte: Westle (2007, p. 95).

O esforço para distinguir entre apoio difuso e apoio específico sugere que estes podem variar de modo independente, com diferentes determinantes e consequências para o funcionamento do sistema. O sentido mais primário do apoio difuso é que este se refere à avaliação do que um objeto é ou representa, e não o que ele faz. O apoio difuso consiste, assim, em "a reservoir of favorable attitudes or good that helps members to accept or tolerate outputs to which they are opposed or the effects of which they see as damaging to their wants" (Easton, 1975, p. 444).

No que diz respeito às propriedades do apoio difuso, Easton argumenta que ele tende a ser mais durável do que o apoio específico, o que não significa que nunca mudará ou que não possa flutuar em períodos curtos. Em geral, o nível de apoio difuso será independente dos outputs e da performance do sistema a curto prazo. No entanto, considera que a relação entre apoio difuso e performance é complexa e necessita ser qualificada. Assim, se o descontentamento com a performance continuar por um longo período, é possível que até vínculos fortes de compromisso possam declinar.

Easton (1975) já ressaltava que o apoio difuso é mais bem interpretado multidimensionalmente, o que significa que é necessário distinguir os determinantes de cada um dos seus componentes. Ao fracionar o conceito nos seus componentes, é possível proporcionar a base para ampliar as explicações e enriquecer o entendimento sobre as consequências sistêmicas.

A legitimidade é definida como a convicção de que é certo e adequado aceitar as exigências do regime e obedecer a elas. Além disso, "It reflects the fact that in some vague or explicit way he sees these objects as conforming to his own moral principles, his own sense of what is right and proper in the political sphere" (Easton, 1965, p. 278). Ela também é compreendida como uma qualidade atribuída às normas e à estrutura do regime, sendo essa crença necessária para a manutenção do apoio político, especialmente nos sistemas políticos que persistem por um período considerável.

Convém ressaltar que, em Easton, não há exatamente uma conexão entre legitimidade e democracia, isso porque a primeira está inserida na análise como um aspecto do apoio difuso e refere-se, assim, aos regimes políticos em geral, sejam eles democráticos ou autocráticos.

A maioria dos estudos emprega o conceito de apoio político da forma como definido por Easton (Hurrelmann, Schneider e Steffek, 2007). Uma possível motivação para esse autor circunscrever o debate no âmbito do apoio político seria um esforço de diferenciar a abordagem empírica de concepções normativas bastante em voga na época, as quais 
possuíam uma filiação teórica ligada à tradição jurídica. Ao examinar a história da legitimidade enquanto um conceito teórico, Hurrelmann, Schneider e Steffek (2007) destacam que a abordagem normativa possui a linhagem intelectual mais antiga. O termo legitimidade tem origem no vocábulo latino legitimus, que era utilizado tanto na jurisprudência medieval quanto na romana para "characterize a state of affairs that was in accordance with law, justice, and customs" (Hurrelmann, Schneider e Steffek, 2007, p. 4).

A pesquisa empírica sobre o conceito de apoio político foi desenvolvida nos escritos sistêmicos e analíticos de Easton. Entretanto, o autor propriamente não operacionalizou o conceito em pesquisas empíricas, deixando-o aberto às diferentes interpretações (Westle, 2007). Na sua concepção, seria fundamental concentrar os esforços de pesquisa no âmbito do apoio ao regime, tendo essa interpretação sido acompanhada por autores como Lipset (1959) e Linz (1978) ao abordarem a quebra dos regimes democráticos no período do entreguerras (Magalhães, 2018).

Por fim, cabe destacar que, embora a publicação dos estudos de Easton sobre apoio político ter sido posterior ao The civic culture, de Almond e Verba (1963), foi sobretudo através da matriz teórica inaugurada por essa última obra que houve a difusão do conceito no âmbito da ciência política. A distinção operada por esses autores entre as orientações das atitudes dos cidadãos em relação ao sistema político (como o regime democrático), os objetos (as instituições) e os sujeitos (os cidadãos) possibilitou o desenvolvimento de estratégias de mensuração empírica, que permitiram superar o elevado nível de abstração teórica dos estudos de Easton.

\section{Inovações na literatura sobre legitimidade e apoio político pós-1990}

Grande parte dos estudos sobre o tema da legitimidade democrática, realizados no âmbito de sua tradição de pesquisas nas décadas de 1980 e 1990, foi direcionada (1) ao diagnóstico da situação das democracias em termos de legitimidade e (2) aos desenvolvimentos teóricos e metodológicos em torno do conceito de apoio político, especialmente às relações entre o apoio difuso e o apoio específico e seus determinantes. Tais desenvolvimentos permitiram, como veremos, diferentes diagnósticos sobre os distintos contextos empíricos em análise.

Os deslocamentos analíticos na literatura estiveram relacionados especialmente às próprias formas de mensuração, num movimento que Magalhães (2018) denominou de "refinamento das medidas de apoio democrático" (p. 419). Parte dos estudos derivados da tradição eastoniana, em geral, mensurava apoio difuso e apoio específico a partir de perguntas incluídas em surveys que questionavam o eleitor sobre a preferência pela democracia em relação a outros regimes (apoio difuso), a avaliação dos governos e a confiança nas principais instituições políticas e sociais (apoio específico). Contra tais formas de mensuração começaram a ser apontados vários limites e imprecisões, especialmente aqueles relacionados à inexistência de medidas de apoio a alternativas autoritárias de organização política, ou mesmo à falta de controle sobre os diferentes significados 
LEGITIMIDADE DEMOCRÁTICA E APOIO POLÍTICO: INOVAÇÕES RECENTES NO DEBATE INTERNACIONAL

associados à ideia de democracia atribuídos pelos respondentes (Canache, 2012; De Jonge, 2016).

A partir da próxima subseção, veremos algumas inovações teóricas e metodológicas produzidas no debate sobre legitimidade democrática ao longo das últimas três décadas.

\section{A visão multidimensional (Dalton / Norris / Booth e Seligson)}

A partir dos anos 1990, os pesquisadores passaram a empregar nos surveys ${ }^{4}$ noções multidimensionais de legitimidade e apoio político, sendo que Norris $(1999,2011)$, Dalton (2004) e Booth e Seligson (2009) desenvolveram importantes contribuições na reformulação da concepção de Easton.

Norris $^{5}$ (1999, 2011) e Dalton (2004) refinaram a classificação eastoniana sobre os objetos do apoio político e argumentaram acerca da necessidade de diferenciar os componentes do regime político entre três subdimensões: princípios do regime, performance do regime e instituições do regime. Desse modo, os autores analisaram empiricamente a estrutura das cinco dimensões do apoio político, que incluem: comunidade política, princípios do regime, performance do regime, instituições do regime e autoridades políticas. Embora as abordagens dos autores possuam grandes semelhanças, existem algumas diferenciações, especialmente no que diz respeito à compreensão sobre o apoio difuso e o apoio específico.

Norris (2011) enfatizou que o apoio específico se direciona aos políticos eleitos responsáveis por implementar decisões políticas dentro do Estado-nação. Também ressaltou que é esperado que ele oscile no tempo em resposta a fatores contextuais, de curto e médio prazos, que contemplariam a gestão do governo sobre políticas econômicas e sociais e externa, bem como o impacto de acontecimentos internacionais.

A autora considera que a distinção entre apoio específico e apoio difuso é mais plausível teoricamente e convém ser mantida se for entendida mais como um continuum do que uma dicotomia. Tal continuum parte dos níveis mais difusos para os mais específicos em um modelo aninhado, no qual cada componente corresponde a uma série de medidas empíricas.

Em consonância com a compreensão do apoio político em diferentes dimensões, Norris (2011) argumenta que a satisfação com a performance da democracia diverge em relação às aspirações públicas, sendo que a distância entre as aspirações e a satisfação é capturada pelo conceito de déficit democrático.

\footnotetext{
4 "In the past, however, researchers could not systematically measure such perceptions and thus had to rely upon their own judgments as a proxy for legitimacy. With the widespread availability of public opinion data, it has become possible to draw on surveys to measure legitimacy" (Booth e Seligson, 2009, p. 8).

5 Convém destacar que o livro Democratic deficit: critical citizens revisited, publicado em 2011, revisita a análise desenvolvida em The critical citizens: global support for democratic government, de 1999. A análise realizada no artigo se concentrará na obra revisitada.
} 
Foi através da concepção de déficit democrático que Norris chegou à identificação do fenômeno dos cidadãos críticos, tema marcante em sua obra (Norris, 2001, 2002) e que é uma característica central de sua análise da legitimidade política no contexto das democracias avançadas. Para essa autora, o cidadão crítico seria uma espécie de "eleitor mediano" dos países centrais, ao conjugar aspirações democráticas como forma ideal de governo e ceticismo em relação ao funcionamento efetivo das instituições democráticas.

Dalton (2004), por sua vez, destaca que Easton contrastou o apoio específico, mais diretamente vinculado às avaliações do objeto político, com o apoio difuso, que refletiria as orientações mais generalizadas e afetivas. Em suas formulações, Dalton considera importante diferenciar entre os elementos afetivos e avaliativos do apoio político ao analisar a opinião pública. Assim, as avaliações referem-se aos julgamentos sobre os fenômenos políticos (apoio específico) e as orientações afetivas gerais representam a aderência aos valores (apoio difuso). Convém mencionar que, para Dalton, cada objeto político é sujeito tanto ao apoio difuso quanto ao específico, desse modo, os objetos podem ser difusos e específicos ao mesmo tempo, o que é distinto da compreensão de Norris (Torcal e Moncagatta, 2011).

A vasta obra empírica desenvolvida por Dalton no contexto das democracias avançadas (Dalton, 2008, 2012, 2019) tem diagnosticado, no âmbito do debate sobre legitimidade, a emergência dos chamados cidadãos assertivos, os quais apresentam baixa confiança nas instituições políticas, forte apoio aos princípios da democracia mas fraco apoio a esses princípios na prática (democratas insatisfeitos); no ativismo político, destacam-se as expressões que desafiam as elites (Dalton e Welzel, 2014).

Cabe mencionar a proximidade dos diagnósticos empíricos feitos por Norris e Dalton sobre a legitimidade no contexto das democracias avançadas. Podem-se buscar as origens dessa semelhança no fato de que ambos os autores tomam como parâmetro analítico a teoria da mudança cultural originalmente proposta por Inglehart (1977) e que culminou numa abrangente e ambiciosa teoria do desenvolvimento humano em Inglehart e Welzel (2009)6.

Uma última referência importante sobre visão multidimensional da legitimidade foi aquela desenvolvida por Booth e Seligson (2009). Os autores compartilham da perspectiva multidimensional do apoio político, no entanto, desenvolveram as suas contribuições mobilizando o conceito de legitimidade democrática, e não o de apoio ao regime, como fizeram Norris (2011) e Dalton (2004). Embora em parte da revisão teórica desenvolvida por Booth e Seligson (2009) haja um emprego da legitimidade e do apoio político em sentido semelhante, uma explicação para o foco na primeira está na própria disposição da análise realizada, considerando-a em três aspectos: a estrutura, as fontes e os efeitos.

\footnotetext{
${ }^{6}$ A teoria do desenvolvimento humano enfatizou o processo de mudança dos valores em direção a uma postura pós-materialista, na qual os indivíduos possuiriam maior autonomia e autoexpressão. Essa mudança nos valores estaria vinculada ao desenvolvimento econômico que ocorreu nas sociedades industriais no período pós-guerra. Tal mudança provocaria alterações no campo religioso, no mundo do trabalho, nas relações de gênero e na participação política, que estaria voltada para as modalidades não convencionais. Em síntese, os valores pós-materialistas contribuiriam para o apoio mais sólido à democracia.
} 
Vale assim destacar a preocupação de Booth e Seligson com os efeitos da legitimidade para a estabilidade política, ou seja, pode-se considerar que a centralidade na legitimidade, e não estritamente no apoio político, decorre, ao menos em parte, da preocupação com as consequências da primeira. Outra possível explicação para o emprego do conceito reside também no fato de o próprio objeto de análise estar circunscrito aos países da América Latina, que não constituem democracias consolidadas (diferentemente das abordagens mencionadas anteriormente), e para os quais a análise sobre a instabilidade e a ruptura dos regimes possuiria um papel ainda mais central.

Assim sendo, Booth e Seligson (2009) encontraram em suas análises seis dimensões da estrutura da legitimidade democrática, as quais estão agregadas do nível mais difuso ao mais específico, seguindo também a conceitualização de Easton: 1) existência de uma comunidade política (a mais básica e difusa das seis dimensões); 2) apoio aos princípios do regime; 3) apoio às instituições do regime; 4) avaliação da performance do regime (itens sociotrópicos da performance econômica); 5) apoio ao governo local; 6) apoio aos atores políticos ou autoridades (p. 49).

É relevante destacar que Booth e Seligson acrescentaram mais uma dimensão na multidimensionalidade da legitimidade. Logo, além das cinco dimensões propostas por Norris (1999, 2011) e Dalton (2004), identificaram o apoio ao governo local como sexta dimensão (Rennó et al., 2011). Booth e Seligson argumentam que a legitimidade molda o comportamento político concreto de modo que este pode reforçar ou minar a democracia.

A abordagem empírica empregada por Booth e Seligson para tratar do apoio à democracia foca mais no endosso das normas e práticas democráticas pelos cidadãos do que na preferência por tipos de regime em abstrato7. Como salienta Magalhães (2018), trata-se de uma das abordagens que têm sido amplamente adotadas e consiste em evitar a inclusão de questões no survey que se refiram diretamente ao tipo de regime. Em linhas mais gerais, o foco nos princípios do regime tem contribuído para enfatizar que as preferências pela democracia não estariam tão enraizadas como, em geral, os pesquisadores haviam destacado ${ }^{8}$. A visão de legitimidade desenvolvida por Booth e Seligson é implícita por enfocar os princípios do regime, evitando e criticando a utilização de perguntas diretas sobre a democracia em decorrência da desejabilidade social.

Os países da América Latina analisados exibiram altos níveis de crença na existência de uma comunidade política, bem como elevado apoio aos princípios do regime.

\footnotetext{
7 Booth e Seligson identificam dois problemas quando a palavra "democracia" é incluída para medir os princípios do regime. O primeiro problema é a questão da desejabilidade social, que pode tornar difícil aos respondentes expressarem o apoio à ditadura. Segundo, os surveys têm mostrado que públicos particulares interpretam os itens de modo diferente. Nesse sentido, argumentam que: "researchers should avoid the term democracy per se when attempting to measure regime legitimacy norms and ask instead about key principles of democracy using more neutral terminology" (Booth e Seligson, 2009, p. 42).

${ }^{8}$ Em síntese, "the move to focus on regime principles, therefore, ultimately helped to underscore the growing impression that global preferences for 'democracy' were not as deeply rooted as scholars had previously thought to be the case. Instead such preferences were seen as essentially coexisting alongside a range of less liberal views which questioned the importance of dissent and the exercise of political freedoms, particularly among ethnic minorities, as well as the value of political participation itself" (Magalhães, 2018, p. 421).
} 
Já as avaliações de atores políticos, governo local e performance do regime apresentaram os piores valores e as maiores variações entre os países. Booth e Seligson consideram que a contribuição das variáveis contextuais é bastante limitada no estudo, o que significa que as variações nas dimensões da estrutura da legitimidade derivam de características mais individuais do que contextuais. Os resultados empíricos apontam que os níveis de legitimidade não seriam baixos o suficiente de modo a produzirem efeitos nos comportamentos e atitudes dos cidadãos que minem as instituições democráticas na América Latina.

Booth e Seligson (2009) destacam ainda que várias possíveis relações entre participação política e legitimidade permanecem pouco exploradas na literatura. Os autores identificaram uma relação entre legitimidade e participação política ${ }^{9}$ no formato de $U$, ou seja, aqueles que mais apoiam o regime, bem como os mais desafetos dele, tendem a participar mais intensamente do que os indiferentes ${ }^{10}$. Tanto a alta quanto a baixa aprovação da performance do governo motivariam os cidadãos a participar na competição eleitoral.

Cabe mencionar ainda que a concepção de legitimidade democrática na perspectiva multidimensional, conforme elaborada por Booth e Seligson (2009), possui desdobramentos importantes nos trabalhos de pesquisadores latino-americanos e, de modo especial, entre os de brasileiros. Essas análises não apropriam de modo homogêneo suas proposições, variando de abordagens mais próximas do conceito de legitimidade democrática (Veiga et al., 2017) a análises que enfocam mais as contribuições da abordagem do apoio aos princípios do regime na formação de um sistema de crenças (Carlin e Singer, 2011; Casalecchi, 2018; Fuks et al., 2016; Fuks, Casalecchi e Ribeiro, 2019) ou às atitudes democráticas (Casalecchi, 2018). Em comum, esses trabalhos ampliam o escopo de análise para um número maior de países da América Latina com dados do Latin American Public Opinion Project (Lapop) e, em sua maioria, utilizam a modelagem multinível para tratar principalmente da influência do contexto econômico e político desses países ${ }^{11}$.

Por fim, fazendo um balanço geral da abordagem multidimensional, ela trouxe importantes avanços analíticos ao questionar as abordagens explícitas, diretas, sobre a democracia, compreendendo o fenômeno da legitimidade de modo mais amplo, juntamente com a preocupação da operacionalização empírica em um conjunto de variáveis. O emprego da metodologia de análise multinível possibilitou identificar a influência de fatores contextuais dos países e tornou-se influente para pesquisas

\footnotetext{
${ }^{9}$ Booth e Seligson analisaram quatro modos de participação política em suas análises: votar e registro para votar; ativismo político e partidário de campanha; contato com funcionários públicos; e ativismo comunal. 10 "Most importantly, in a striking finding with only a few exceptions, the main pattern of relationships between legitimacy and participation (...) is U-shaped - that is, both the most supportive and the most disaffected citizens are more active than citizens holding middling legitimacy norms" (Booth e Seligson, 2009, p. 157).

11 Sobre o caso brasileiro, vale destacar o já clássico estudo de Moisés (1995), "Os brasileiros e a democracia", que representa o primeiro estudo sistemático sobre apoio à democracia pós-redemocratização. Um balanço dos estudos sobre legitimidade e apoio político no Brasil foi feito por Borba e Cardoso (2019).
} 
posteriores. Um dos limites da abordagem multidimensional está principalmente nos tipos de diagnósticos produzidos sobre a democracia. Assim sendo, podemos destacar um certo otimismo nas análises de Dalton e Norris sobre os cidadãos críticos e assertivos, o qual passou a ser desconstruído com a emergência dos partidos e candidatos de extrema direita nos mais diversos países na última década.

\section{A legitimidade como produto das visões e da avaliação da democracia}

A obra How Europeans view and evaluate democracy, organizada por Ferrín e Kriesi (2016), mobilizou diversos pesquisadores europeus e realizou contribuições importantes do ponto de vista teórico, metodológico e empírico. Ela é orgânica e original, tanto no sentido das conexões estabelecidas pelos autores no decorrer dos capítulos quanto ao desenvolver uma abordagem própria para a compreensão da legitimidade democrática, como produto da visão e da avaliação da democracia pelos eleitores. Trata-se, assim, de uma abordagem teórica que não está filiada à tradição de Easton e não está ancorada conceitualmente na distinção entre apoio difuso e apoio específico, diferenciando-se, desse modo, das formulações de Dalton (2004), Norris (2011) e Booth e Seligson (2009).

Muito da pesquisa anterior acerca do modo como os cidadãos veem e avaliam a democracia baseou-se no conceito de apoio político de Easton, e o conceito tem sido utilizado por muitos autores, de diferentes modos. Nesse sentido, Ferrín e Kriesi consideram que a relação entre os objetos do apoio (comunidade política, regime e autoridades) e os seus tipos (difuso e específico) está entrelaçada de um modo confuso, e uma separação entre objetos e tipos poderia propiciar um melhor entendimento do fenômeno. Haveria ainda uma confusão na literatura entre a forma como o apoio político é definido e a forma como é explicado, ou seja, entre o que ele é e quais são as suas fontes.

Para simplificar essa discussão, Ferrín e Kriesi (2016) propõem uma alternativa conceitual que consideram mais fácil de identificar empiricamente em relação à abordagem de Easton. Os autores distinguem entre as visões da democracia, relacionadas ao ideal normativo referente a esse regime, e as avaliações da democracia, que se referem à avaliação do modo como os princípios estão implementados:

Views of democracy refer to the citizens' normative ideal of democracy, their ideas about what democracy should be. Evaluations of democracy, instead, refer to the citizens' assessment of the way the democratic principles have been implemented in their own country - their evaluation of the way the different aspects of democracy work in their own country (Ferrín e Kriesi, 2016, p. 10).

A distinção entre visão e avaliação torna-se central para o debate sobre legitimidade, pois é a comparação entre os ideais democráticos e o funcionamento atual da democracia que possibilita o julgamento dos eleitores sobre um regime democrático. 
Na maior parte do tempo, a legitimidade é concebida como um conceito formado por um conjunto de avaliações do sistema político ou um conjunto de indicadores de apoio para diferentes objetos ${ }^{12}$, havendo pouco esforço em gerar uma medida direta das crenças democráticas dos cidadãos (Ferrín e Kriesi, 2016). Para o desenvolvimento teórico e analítico, o estudo utilizou as bases de dados do European Social Survey (ESS) da Rodada 6 (2018), que possibilitaram operacionalizar os conceitos e desenvolver a primeira análise das visões dos europeus e suas avaliações sobre a democracia (Kriesi e Morlino, 2016).

Ferrín e Kriesi, bem como os demais autores, consideram que a maior parte dos cidadãos não adota um único modelo teórico de democracia, e sim visões que são compatíveis com vários modelos ao mesmo tempo. Assim sendo, os autores defendem uma concepção ampla de democracia que inclua um conjunto maior de atributos. As visões dos cidadãos sobre a democracia são analisadas na obra considerando três grupos: a visão liberal, a justiça social e a democracia direta. O grupo liberal é dividido entre os componentes eleitorais e liberais, sendo que os indicadores relacionados à competição eleitoral capturam a essência da democracia representativa ao avaliar a importância que os cidadãos atribuem às eleições livres e justas. Já os elementos liberais abrangem os indicadores relacionados com os princípios liberais, os quais garantem os direitos civis básicos dos cidadãos e limitam o poder do Estado.

Os outros dois grupos, justiça social e democracia direta, correspondem a dois modelos de democracia que vão além do modelo básico de democracia liberal, mensurando assim, em primeiro lugar, quanto os cidadãos consideram ser importante para as democracias a redução das desigualdades de renda e, em segundo, quanto eles consideram que os governos deveriam proteger todos os cidadãos contra a pobreza.

Nas análises empíricas, as avaliações da democracia são consideradas de acordo com as diferentes visões (liberal, justiça social e democracia direta), e não de modo único, pois os autores ressaltam que as visões que os cidadãos possuem dos diferentes aspectos da democracia influenciam fortemente nas avaliações da performance democrática. Além disso, as avaliações da democracia seriam dependentes dos resultados sociais e econômicos do sistema político, pois "the more one is satisfied with the output of public policies or the state of economy, the better one's evaluation of democracy, confirming once more the relative importance of this set of factors in the evaluation of democracy" (Torcal e Trechsel, 2016, p. 216).

A abordagem da legitimidade como produto das visões e da avaliação desenvolvida na obra How Europeans view and evaluate democracy considera que uma maneira de criar uma medida de legitimidade seria realizar uma comparação entre o "deveria" (as visões) e o "é" (as avaliações) (Weßels, 2016). Desse modo, essa abordagem está alinhada com

\footnotetext{
12 "Most of the time, legitimacy is conceived as a formative concept defined either by a set of evaluations of the political system (Levi, Sacks, and Tyler 2009; Weatherford, 1992) or by several indicators of support for different objects of the political system - such as trust in political parties and regime performance (Booth $e$ Seligson, 2009)" (Ferrín e Kriesi, 2016, p. 12).
} 
o argumento teórico segundo o qual, na avaliação da legitimidade, é relevante que os cidadãos usem as suas próprias referências e não referências impostas externamente.

Uma distinção importante desenvolvida no decorrer da obra é a diferenciação sistemática entre as características individuais e contextuais em decorrência da premissa de que não é possível estudar as atitudes dos cidadãos sobre democracia independentemente do país em que vivem, tendo em vista que as características individuais desempenham o papel de determinar como os cidadãos veem a democracia enquanto um ideal (Ferrín e Kriesi, 2016; Kriesi e Morlino, 2016). Dessa forma, a análise multinível é empregada de modo sofisticado, sendo que os estudos empíricos avançam em um tipo de análise menos explorado na literatura, que consiste em considerar as interações entre os níveis micro e macro (indivíduo e contexto), as cross-level interactions ${ }^{13}$.

A Figura 1 possibilita realizar uma síntese das formulações teóricas, analíticas e metodológicas desenvolvidas na obra How Europeans view and evaluate democracy (Weßels, 2016). Desse modo, os fatores contextuais e os fatores individuais são mobilizados de modo entrelaçado para explicar as visões e avaliações da democracia. A legitimidade democrática, por sua vez, é produzida na relação entre as visões e as avaliações da democracia. Os indicadores mais clássicos e consolidados, como apoio à democracia e satisfação com a democracia, também são discutidos e considerados nas análises.

Figura 1

Visões, avaliações e legitimidade democrática

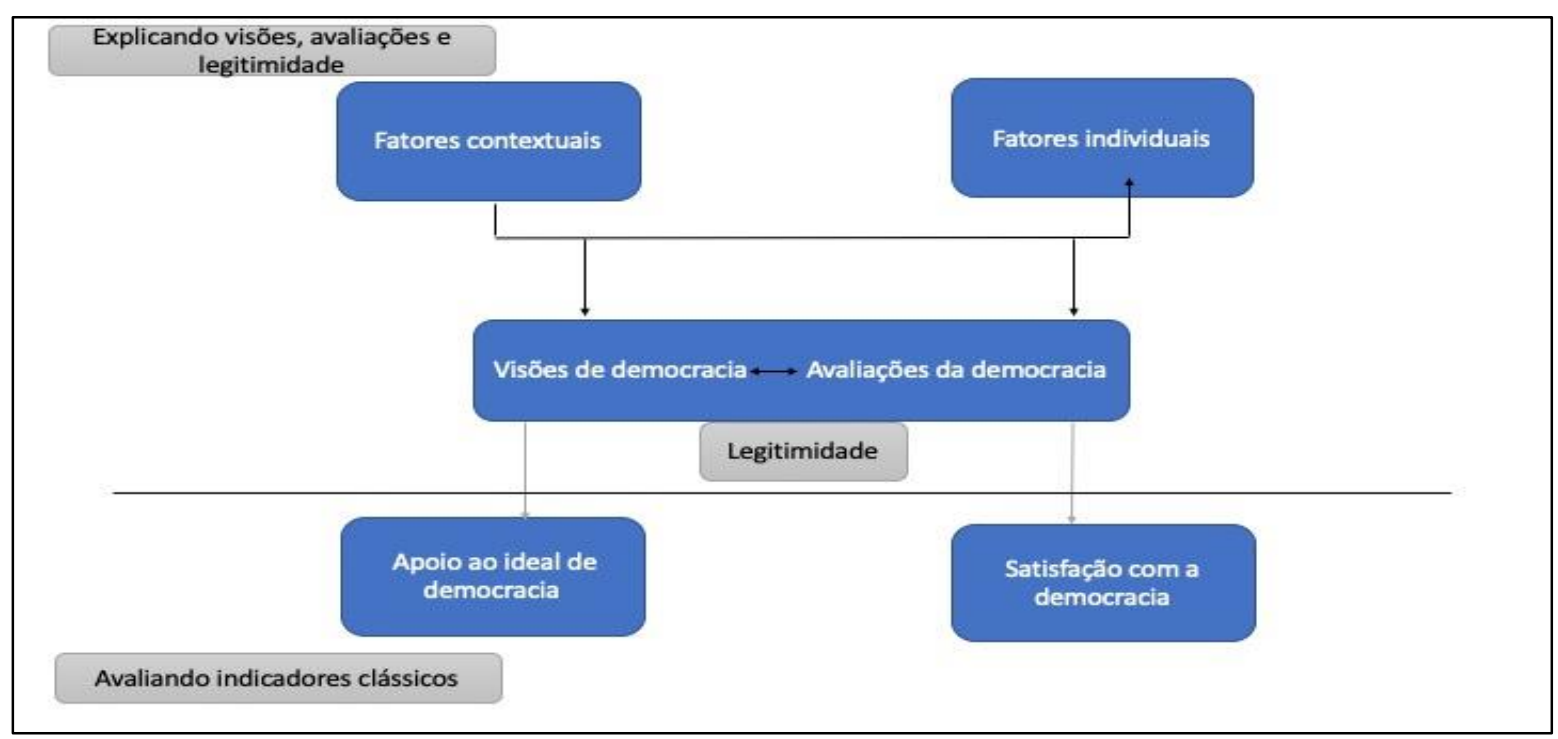

Fonte: Figura adaptada de Ferrín e Kriesi (2016, p. 14).

\footnotetext{
13 "Most importantly, however, our empirical analyses have shown that the impact of individual characteristics is contingent on the context in which the individuals have their experiences with democracy. The neglect of these cross-level interactions' in much of the literature on political support and democratic legitimacy has often led to weak, inconclusive, or contradictory results" (Kriesi e Morlino, 2016, p. 320).
} 
Vale também mencionar que as consequências das visões e avaliações da democracia não foram totalmente exploradas, e ainda permanecem em aberto as consequências destas para o comportamento político dos europeus, como, por exemplo, em que medida o grau de legitimidade interfere na escolha eleitoral (Kriesi e Morlino, 2016). Cabe ainda salientar que a questão da participação política em suas diferentes modalidades não está presente nas análises, o que pode ser considerado uma lacuna dessa abordagem, tendo em vista a relevância da participação política para outras concepções de legitimidade.

No geral, os resultados empíricos apontam que os europeus possuem uma ampla visão liberal que inclui tanto componentes eleitorais e liberais como componentes centrais da visão de democracia. Entretanto, as visões sobre a democracia não são limitadas ao modelo democrático liberal, sendo que os europeus também aderem a outras visões em adição a esse modelo (Kriesi e Morlino, 2016). Eles não parecem suficientemente satisfeitos com a qualidade da prática democrática em seus países, pois haveria uma percepção generalizada de que as instituições democráticas falham em cumprir as aspirações democráticas, especialmente no que diz respeito ao rule of law, justiça social e elementos de democracia direta (Gómez e Palacios, 2016) ${ }^{14}$.

\section{Legitimidade como sistema de crenças}

Boa parte dos trabalhos de Ryan Carlin tem abordado os países da América Latina como objeto empírico. O autor desenvolveu vários estudos (Carlin, 2011; Carlin e Singer, 2011; Carlin, Love e Singer, 2014; Carlin e Moseley, 2015) dialogando especialmente com o modelo teórico desenvolvido por Booth e Seligson (2009). Em estudo recente (Carlin, 2018), buscou inovar nessa agenda de pesquisas, construindo um modelo sobre a legitimidade democrática no qual propõe uma articulação com o clássico debate sobre sistema de crenças (Converse, 1964), em uma abordagem indutiva sobre o tema. A questão central em seu estudo é examinar padrões de representações subjetivas e comportamentais do apoio democrático, e a partir daí estimar quais e quantos perfis estão relacionados às crenças sobre a democracia.

Em termos conceituais, a distinção entre apoio político e legitimidade não é diretamente tematizada no estudo de Carlin (2018). Seu ponto de partida é uma tentativa de articular as visões implícitas, explícitas e aqueles aportes que ele denomina de híbridos sobre o apoio à democracia. Esses últimos seriam tentativas de mensuração usando medidas explícitas (questões sobre preferência pela democracia versus preferência por outros regimes) e implícitas (questões sobre determinados princípios democráticos) através de estratégias de cluster analysis (Seligson e Carrión, 2002; Carlin, 2011; Recabarren e Maldonado, 2010; Schedler e Sarsfield, 2007; PNUD, 2004). O problema

\footnotetext{
14 Tanto os elementos eleitorais quanto os liberais são os mais bem ranqueados, já os elementos sociais e os da democracia direta obtêm os piores escores. Os dados apontam para a existência de um gap entre o ideal e a prática percebida das democracias na Europa.
} 
dessas abordagens, segundo o autor, seria o fato de que elas não ponderam o peso dos valores e crenças, uns em relação aos outros. Isso tem implicações analíticas sérias, pois a força relativa de cada elemento tem impactos sobre o tipo de orientação e sobre a própria natureza do vínculo que o cidadão vai ter com a democracia (Carlin, 2018).

Como forma de superar esses limites, o autor propõe o uso de uma técnica qualitativa inicialmente utilizada na psicologia, chamada de Q-sort, empregada para fins de agrupamento de dados de modo a revelar padrões de subjetividade em estudos com pequeno número de casos. Nas palavras do autor: "Unlike surveys and interviews, Q-sorts allow individuals to reveal their belief systems behaviorally and to assign the appropriate weight of the orientations they contain" (Carlin, 2018, p. 2). O estudo empírico foi realizado no Chile e na Argentina e contou com grupos focais e entrevistas.

Por se tratar de uma abordagem híbrida, seu modelo parte de uma definição mínima de democracia (Collier e Levitsky, 1997), caracterizando como democratas aqueles "unconditionally committed to elections and the ideals of political tolerance and individual liberty" (2018, p. 5). Diante disso, Carlin (2018) usa como parâmetro de sua análise três classes de objetos constitutivos do sistema de crenças democráticas: a dimensão iliberal/ liberal, a dimensão incondicional/condicional e a dimensão comprometido/não comprometido.

Sua pesquisa empírica encontrou sete perfis de "sistema de crenças" nas duas cidades analisadas. Tais perfis são produto da combinação entre as três dimensões e os pesos de determinados valores que estão presentes nos indivíduos. São eles: em Santiago, "democratic", "delegative", "fair weather" e "nondemocrat". Em Buenos Aires, "popular", "exclusionary", "delegative". Para exemplificar, um perfil que é comum às duas cidades: "delegative support". Em ambas, a referência é a concepção de O’Donnell (1991) sobre "democracia delegativa", que implica uma adesão a uma visão "iliberal" de democracia; porém, a forma como a concepção delegativa se materializa em cada uma das cidades possui algumas diferenças. Os eleitores de ambas preferem "democratic governance, dislike military intervention, and waffle on human rights" (p. 14), porém, enquanto os chilenos possuem uma visão mais "caudilhista" de delegação, os eleitores de Buenos Aires estão mais próximos de uma visão "populista".

Com esses resultados, o estudo de Carlin (2018) oferece uma interessante abordagem para o estudo qualitativo da legitimidade democrática. Além disso, a desagregação dos componentes do sistema de crenças torna possível a inclusão de novas questões nas pesquisas de opinião pública.

As características de um desenho de pesquisa qualitativo tornam difícil a comparação com outros estudos desse campo, porém a articulação feita por Carlin entre os estudos de legitimidade e a teoria do sistema de crenças oferece a oportunidade para a construção de uma nova agenda de pesquisas que guarda alguma similaridade com o estudo de Ferrín e Kriesi (2016) resenhado acima. Em outras palavras, tal agenda permite identificar os diferentes significados da legitimidade política no eleitorado. 


\section{A legitimidade como desejabilidade social}

Conforme vimos até aqui, a grande maioria dos estudos sobre legitimidade democrática utiliza dados de survey como base empírica. Para tanto, várias estratégias de mensuração e baterias de perguntas foram desenvolvidas e validadas ao longo de mais de 50 anos de pesquisa sobre o tema. Os recentes trabalhos desenvolvidos por Graham e Svolik (Graham e Svolik, 2020; Svolik, 2020) colocam uma outra perspectiva sobre tal agenda de pesquisas, usando, para tanto, dados experimentais.

A tese central de tais estudos é que as medidas clássicas de apoio à democracia, especialmente aquelas explícitas, convidam o respondente a uma "resposta socialmente desejável" ou "politicamente correta" ao confrontar o eleitor com a opção pela democracia versus opção por outros regimes políticos.

Já os experimentos de "candidato/escolha" desenvolvidos pelos autores permitiriam, segundo eles, mensurar tal apoio de maneira indireta ou implícita, porém apresentando situações do mundo real. Dessa forma, "acredita-se que os respondentes 'apoiem a democracia' não quando dizem fazê-lo, mas quando suas escolhas revelam uma disposição para colocar princípios democráticos acima de interesses sectários" (Svolik, 2019, p. 2).

Apesar de não haver uma preocupação conceitual em distinguir legitimidade e apoio político, ficam evidentes nas análises as insuficiências empíricas da tradição de pesquisas derivada da concepção eastoniana. Pode-se argumentar que, da abordagem proposta, deriva uma ideia de que a legitimidade seria uma concepção forte de adesão que implicaria compromissos morais profundos entre o cidadão e o regime político a que ele está vinculado. Compromissos esses relacionados aos princípios, e não somente a uma ideia abstrata de "democracia" ou "autoritarismo", ou mesmo ao apoio a instituições específicas como o parlamento.

Segundo Svolik (2019), as medidas clássicas de apoio difuso e apoio específico teriam o limite de não captarem a preferência do eleitorado por princípios democráticos quando "estes competem com outras opções" (p. 17). Em ambientes polarizados, as clivagens sociais ficam expostas, e as eleições passam muitas vezes a ser momentos de decisão entre a defesa de interesses de grupo versus a defesa de princípios democráticos. A tese é que, em tais contextos, a democracia tende a ser sacrificada pelo próprio povo, pois "a polarização corrói a capacidade de um eleitorado resistir ao autoritarismo" (p. 20).

Em termos empíricos, o ponto de partida de Svolik são os debates recentes sobre populismo, polarização política e recessão democrática. Para ele, a nova onda de regimes autoritários ao redor do mundo tem como característica central "a tomada de poder pelo Executivo", de modo que a subversão da democracia tem sido feita por lideranças políticas eleitas democraticamente e contando com respaldo popular (Mounk, 2019). Sua questão, então, é saber por que o povo aceita abrir mão da democracia.

A resposta é que, em contextos de polarização política, aqueles eleitores situados nos extremos ideológicos ou partidários aceitam abrir mão da democracia para evitar que 
os grupos oponentes cheguem ao poder. Em outras palavras, os eleitores trocam democracia por partidarismo ou ideologia.

Os estudos empíricos desenvolvidos para chegar a essas conclusões foram feitos em contextos os mais variados, como Venezuela (Svolik, 2020), Estados Unidos (Graham e Svolik, 2020) e Turquia (Svolik, 2019). A estratégia empírica, conforme mencionamos acima, foi a aplicação de experimentos de survey do tipo "candidato/escolha". Usando amostras representativas do eleitorado de cada país, foram apresentados dois candidatos hipotéticos aos respondentes. Cada candidato foi descrito a partir de características sociodemográficas e de aspectos reais do sistema político de cada país, como seu partido político e propostas programáticas típicas da plataforma partidária que representaria. Além disso, através de designação aleatória, alguns candidatos foram apresentados como defendendo uma proposta que violaria algum princípio democrático, guardando correspondência com issues reais dos países, e que em algum momento foram utilizados de fato pelos líderes políticos que buscam subverter a democracia ${ }^{15}$.

Os resultados foram surpreendentes: em todos os três países, os eleitores extremistas (partidários ou ideológicos) aceitariam abrir mão de princípios democráticos, desde que fosse para derrotar o candidato/partido oponente. E isso vale mesmo para eleitores que respondiam positivamente às perguntas clássicas sobre preferência/apoio à democracia. Nas palavras de Svolik (2019, p. 12), "os eleitores relutam em punir políticos que desrespeitam princípios democráticos quando fazê-lo exige abandonar seu partido ou políticas favoritas".

Uma segunda descoberta do estudo é que, nos três países estudados, aqueles eleitores localizados no centro ideológico e/ou com preferências partidárias fracas ou independentes são os que menos estão dispostos a abrir mão de princípios democráticos. Segundo Svolik, os centristas exerceriam um papel de guardiões da democracia, perfil esse que é um recurso escasso em sociedades polarizadas.

\section{A legitimidade como humor}

Um dos mais ambiciosos trabalhos recentes sobre legitimidade democrática tem sido realizado por Claassen (2020) ao aplicar o conceito de "mood", inicialmente desenvolvido no campo dos estudos "macro" de opinião pública para analisar fenômenos como avaliação de governo (Erikson, Mackuen e Stimson, 2002; Soroka e Wlezien, 2010; Wlezien, 1995). O enquadramento teórico de tais estudos concebe a dinâmica da opinião

\footnotetext{
15 "Na Turquia, por exemplo, uma das medidas propunha demitir servidores públicos que não apoiassem o partido do candidato, e outra sugeria substituir juízes que parecessem enviesados contra o partido do candidato. Na Venezuela, um conjunto de medidas focava em mudar a composição da comissão eleitoral: as opções eram manter o significativo viés pró-governo da comissão eleitoral à época do estudo, enviesá-la ainda mais indicando mais chavistas ou eliminar esse viés indicando uma comissão politicamente independente. Nos Estados Unidos, foram apresentados candidatos que disputavam eleições estaduais (em vez da federal) e que apoiavam uma gama de políticas não democráticas historicamente adotadas no nível estadual. Algumas, como a supressão de voto por meio de gerrymandering, persistem até hoje" (Svolik, 2019, pp. 10-11).
} 
pública operando na forma de um "thermostatic model": "when government spending increases, citizens prefer that it decrease; where policy shifts to the right, citizens' preferences move to the left" (Claassen, 2020, p. 36). Ao aplicar tal referencial, o autor se afasta da matriz eastoniana sobre apoio político e sua distinção entre as dimensões difusa e específica da legitimidade.

Aplicando esse referencial ao estudo da legitimidade democrática, o autor afirma que "publics would clamor for democracy when it is scarce, but their preference for democracy would weaken as democratic rights and institutions are supplied" (Claassen, 2020 , p. 36). A grande inovação desse estudo para o campo de pesquisas sobre apoio político foi a proposta de uma análise dinâmica que avalia como mudanças nos níveis de democracia ocasionam mudanças no apoio democrático, em vez de enfocar correlações estáticas entre os dois planos.

De modo a operacionalizar tal perspectiva, Claassen (2020) mobiliza uma quantidade monumental de dados de pesquisa de opinião pública de 135 países, cobrindo o período de 1988-2018. Foram usados 14 "survey projects", gerando 1.391 surveys. Para estimar sua variável dependente, o "democratic mood", o autor usou medidas de país/ano, aplicando um modelo bayesiano de variáveis latentes desenvolvido em estudo anterior (Claassen, 2019). As variáveis utilizadas foram todas aquelas questões explícitas sobre apoio à democracia utilizadas nos surveys, relacionadas à: (1) desejabilidade da democracia; (2) comparação da democracia com outros regimes políticos; ou (3) avaliação de outras formas de governo não democráticas.

Já a variação do mood seria explicada por avanços em medidas de democracia. Para tanto, Claassen usou três índices do projeto Varieties of Democracy (V-DEM): o "electoral democracy index", o "liberal component index" e o "liberal democracy index". Enquanto o primeiro mensura os elementos propriamente poliárquicos de um país, o segundo está relacionado às suas características "contramajoritárias", no sentido da capacidade de proteger direitos de minorias. Já o terceiro é a conjunção dos dois primeiros.

Conforme adiantamos, suas hipóteses eram de que avanços democráticos verificados nos países (mensurados pelos respectivos índices) causassem diminuição do apoio à democracia. Os resultados indicaram que o "democratic mood" é sim influenciado pelo avanço da democracia, mas somente em seu aspecto contramajoritário. Nas palavras do autor: "It is not improvements in majoritarian institutions and processes that damage democratic mood, but, instead, increased legislative and judicial oversight and enhanced protections of minority and individual rights which provoke the backlash" (Claassen, 2020, p. 50).

As implicações de tais resultados para o debate sobre legitimidade democrática são amplas. Eles questionam os pressupostos das teorias culturalistas ou institucionalistas que afirmam que a democracia cria sua própria demanda (Dahlum e Knutsen, 2016), e os cidadãos aprenderiam sobre a democracia por meio do seu exercício/prática (socialização intergeracional) ou de seus resultados (performance das instituições). Para Claassen, a produção da legitimidade democrática é mais complexa que isso. Ela é produto da reação 
do público às mudanças nas instituições democráticas, especialmente quando se trata de proteção de minorias.

Como entender o mecanismo causal aí presente? O autor vai buscar a resposta na literatura sobre "judicial review" e "political tolerance". O argumento é que princípios democráticos gerais, como "governo do povo", são amplamente aceitos socialmente e, em geral, não enfrentam reações de qualquer segmento do eleitorado; porém, a proteção de minorias é um dos aspectos menos aceitos por muitos cidadãos, conforme demonstram os estudos de Gibson (2008), citados por Claassen.

Vale ainda observar que a questão dos efeitos do "mood" democrático na participação política não é algo explorado por Claassen, logo, caberia indagar sobre os possíveis desdobramentos do efeito termostático no comportamento eleitoral, por exemplo. Esse movimento viria acompanhado por uma reação conservadora expressa nas urnas? Consideramos que se trata de um aspecto que também pode ser aprofundado em estudos futuros.

O Quadro 1 apresenta a síntese das diferentes concepções de legitimidade democrática retratadas no artigo: apoio político; multidimensional; produto das visões e avaliações da democracia; sistemas de crenças; desejabilidade social; e humor. Desse modo, destacamos aspectos como o enquadre teórico e o foco analítico principal da abordagem, os respectivos autores(as), bem como os contextos de análise e as metodologias que foram utilizadas nos estudos. Assim sendo, é possível compor um retrato que possibilita a comparação entre as abordagens e a identificação de suas distinções e semelhanças.

Quadro 1

Síntese das concepções de legitimidade democrática

\begin{tabular}{|l|l|c|c|c|}
\hline $\begin{array}{l}\text { Concepções de } \\
\text { legitimidade }\end{array}$ & \multicolumn{1}{|c|}{ Foco principal } & Autores(as) & $\begin{array}{c}\text { Contexto de } \\
\text { análise }\end{array}$ & Metodologia \\
\hline Apoio político & $\begin{array}{l}\text { Distingue entre modos (apoio difuso } \\
\text { e espećfico) objetos do apoio } \\
\text { (comunidade política, regime político } \\
\text { e autoridades políticas). }\end{array}$ & $\begin{array}{c}\text { Easton } \\
(1965,1975)\end{array}$ & - & - \\
\hline Multidimensional & $\begin{array}{l}\text { Apoio político como um fenômeno } \\
\text { multidimensional que expressa um } \\
\text { continuum dos níveis mais difusos } \\
\text { para os mais específicos. }\end{array}$ & $\begin{array}{c}\text { Norris (1999, } \\
2011)\end{array}$ & $\begin{array}{c}\text { Diversos } \\
\text { países }\end{array}$ & $\begin{array}{c}\text { Quantitativa/ } \\
\text { Regressão/ } \\
\text { Análise } \\
\text { multinível }\end{array}$ \\
\hline Multidimensional & $\begin{array}{l}\text { Ennfase nos princípios do regime não } \\
\text { na preferência pela democracia em } \\
\text { abstrato. Foco em estrutura, fontes e } \\
\text { efeitos da legitimidade. Estrutura da } \\
\text { legitimidade compreendida de modo } \\
\text { multidimensional. }\end{array}$ & $\begin{array}{c}\text { Booth e } \\
\text { Seligson } \\
\text { (2009) }\end{array}$ & $\begin{array}{c}\text { América Latina } \\
\text { (oito países) }\end{array}$ & $\begin{array}{c}\text { Quantitativa/ } \\
\text { Modelo de } \\
\text { equações } \\
\text { estruturais/ } \\
\text { Análise } \\
\text { multinível }\end{array}$ \\
\hline
\end{tabular}




\begin{tabular}{|c|c|c|c|c|}
\hline $\begin{array}{l}\text { Concepções de } \\
\text { legitimidade }\end{array}$ & Foco principal & Autores/as & $\begin{array}{l}\text { Contexto de } \\
\text { análise }\end{array}$ & Metodologia \\
\hline $\begin{array}{l}\text { Produto das visões e } \\
\text { avaliações da } \\
\text { democracia }\end{array}$ & $\begin{array}{l}\text { Diferencia as visões (ideal normativo } \\
\text { de democracia) e avaliações da } \\
\text { democracia (avaliação do modo } \\
\text { como os princípios estão } \\
\text { implementados). Legitimidade como } \\
\text { produto da comparação entre as } \\
\text { visões e as avaliaços. Elaboração de } \\
\text { uma tipologia da legitimidade para } \\
\text { os países analisados. }\end{array}$ & $\begin{array}{c}\text { Ferrín e } \\
\text { Kriesi (orgs.) } \\
(2016)\end{array}$ & Europa & $\begin{array}{l}\text { Quantitativa/ } \\
\text { Regressão/ } \\
\text { Análise } \\
\text { multinível }\end{array}$ \\
\hline Sistema de crenças & $\begin{array}{l}\text { Modelo sobre legitimidade em } \\
\text { articulação com o debate clássico } \\
\text { sobre sistema de crenças (Converse, } \\
\text { 1964). Foco nos padrões de } \\
\text { representações subjetivas e } \\
\text { comportamentais do apoio } \\
\text { democrático. }\end{array}$ & Carlin (2018) & $\begin{array}{c}\text { Chile e } \\
\text { Argentina }\end{array}$ & $\begin{array}{c}\text { Qualitativa } \\
\text { Q-sort (grupos } \\
\text { focais e } \\
\text { entrevistas) }\end{array}$ \\
\hline Desejabilidade social & $\begin{array}{l}\text { Legitimidade como uma concepção } \\
\text { forte de adesão que implica } \\
\text { compromissos com as normas de um } \\
\text { regime democrático. Enfoque nas } \\
\text { consequências da polarização } \\
\text { política. }\end{array}$ & $\begin{array}{c}\text { Graham e } \\
\text { Svolik } \\
(2020) \\
\text { Svolik (2019, } \\
2020)\end{array}$ & $\begin{array}{l}\text { Venezuela, } \\
\text { Estados } \\
\text { Unidos, } \\
\text { Turquia }\end{array}$ & Experimentos \\
\hline Humor & $\begin{array}{l}\text { Legitimidade democrática como } \\
\text { produto da reação pública às } \\
\text { mudanças nas instituições } \\
\text { democráticas, especialmente quando } \\
\text { se trata da proteção de minorias. } \\
\text { Modelo termostático. Influência dos } \\
\text { estudos sobre a dinâmica da opinião } \\
\text { pública. }\end{array}$ & $\begin{array}{c}\text { Claassen } \\
(2020)\end{array}$ & $\begin{array}{c}135 \text { países de } \\
1988 \text { a } 2018\end{array}$ & $\begin{array}{l}\text { Quantitativa/ } \\
\text { Séries } \\
\text { temporais - } \\
\text { Análise } \\
\text { longitudinal }\end{array}$ \\
\hline
\end{tabular}

Fonte: Elaboração própria.

\section{Legitimidade, apoio político e as democracias contemporâneas: considerações finais}

Depois de cinco décadas de pesquisa sobre legitimidade, afinal qual a contribuição desse campo de pesquisas para o entendimento das democracias contemporâneas e seus dilemas?

Uma primeira consideração é o reconhecimento de que, desde a publicação dos estudos iniciais de Easton, tal campo de pesquisas experimentou avanços significativos em termos teóricos e metodológicos. Destaque para os desenvolvimentos conceituais que propiciaram a transição entre uma visão unidimensional para uma abordagem multidimensional sobre a legitimidade democrática. Tal transição, como vimos, permitiu o desenvolvimento de novas estratégias de análise, que ampliaram em muito o conhecimento sobre as diferentes dimensões em que o apoio político se manifesta. 
Outro desenvolvimento importante foi a transição de uma abordagem abstrata sobre apoio político para outra focada em questões sobre "princípios do regime". A abordagem abstrata era centrada em perguntas explícitas sobre a preferência por regime democrático versus preferências por outros regimes políticos, que trazia consigo problemas de equivalência comparativa, pois os significados sobre o que é democracia variam de um contexto para outro. Especialmente em função do trabalho de Booth e Seligson (2009), cada vez mais os estudos empíricos analisam a legitimidade a partir de questões sobre a adesão dos cidadãos aos princípios do regime.

Em termos metodológicos, três avanços muito importantes aconteceram: um primeiro, relacionado ao tópico anterior, deu-se através de melhoras contínuas nas medidas diretas e indiretas de apoio à democracia nos diferentes surveys destinados a pesquisas comparativas internacionais sobre atitudes e comportamento político. Destaque aqui para as iniciativas do Barômetro das Américas (Lapop), do World Values Survey (WVS) e do European Social Survey (ESS) ${ }^{16}$. Um segundo avanço metodológico deu-se nas técnicas de análise de dados. Aqui, o uso das mais recentes técnicas multivariadas tem permitido avanços importantes nesse campo de conhecimento. Destaque para a incorporação da modelagem multinível, que tem possibilitado a análise articulada de variáveis individuais e de contexto em estudos comparativos, permitindo novas respostas a problemas antigos da área, que, em geral, esbarravam na "falácia ecológica". O uso de séries temporais tem sido outra importante contribuição metodológica recente, como pode ser verificado no trabalho de Claassen (2020). Um terceiro avanço metodológico foi a incorporação de novos desenhos de pesquisa, especialmente os desenhos experimentais inaugurados pelos estudos de Graham e Svolik (2020), que permitiram enfrentar a crítica da "desejabilidade social" da democracia, a qual era muito difícil de ser confrontada com os recursos metodológicos oferecidos pela pesquisa tipo survey.

Por outro lado, em que pesem os avanços teóricos e metodológicos, dois problemas ainda continuam com respostas insuficientes pelas pesquisas da área. O primeiro é antigo e persistente nas pesquisas sobre cultura política, a falta de clareza e precisão conceitual (Johnson, 2004). Ainda que se tenha avançado muito nas medidas de legitimidade democrática, problemas conceituais continuam sem resolução, o que se reflete em diferentes estratégias empíricas para mensurar apoio político, que acabam produzindo resultados muitas vezes contraditórios.

Acreditamos, porém, que o principal problema do referido campo de estudos é de natureza empírica, especialmente no que se refere ao diagnóstico das democracias contemporâneas. Muito do que se produziu nessa área nos últimos 20 anos foi marcado por um grande otimismo com relação à natureza do vínculo que estaria conectando

\footnotetext{
16 Site do Lapop: <https://www.vanderbilt.edu/lapop/>. Site do WVS: <https://www.worldvaluessurvey.org/wvs.jsp>. Site do ESS: <https://www.europeansocialsurvey.org>. A 6 a rodada do ESS proporciona a oportunidade de descrever sistematicamente e comparar as concepções europeias de democracia, utilizando um número extensivo de indicadores, o que possibilitou o desenvolvimento do projeto "Visões e avaliações da democracia".
} 
cidadãos e sistemas políticos. O modelo multidimensional de Norris (2011), por exemplo, produziu um diagnóstico de que o cidadão típico das democracias avançadas era "crítico". Ele avaliaria negativamente o funcionamento das instituições democráticas, mas teria compromissos morais profundos com a democracia. As consequências políticas desse diagnóstico eram que as democracias não teriam problemas de legitimidade, mas sim que elas contariam com cidadãos cada vez mais equipados cognitivamente, que dependeriam cada vez menos das instituições políticas tradicionais para agirem politicamente. Veja-se que esse mesmo diagnóstico está presente no "cidadão pós-materialista", de Inglehart e Welzel (2009), e no "cidadão assertivo", de Dalton e Welzel (2014). A visão aqui era de que o mundo caminharia em direção a mais democracia, numa visão totalmente teleológica da história. Inglehart e Welzel chegam mesmo a falar em emancipação humana.

Porém, conforme indicamos na introdução, o início do século XXI colocou vários novos desafios para os regimes democráticos. As democracias iliberais (Diamond e Plattner, 2015), os populismos e os novos autoritarismos (Norris e Inglehart, 2019) são evidências de um quadro no mínimo mais complexo do que aquele previsto pelos autores acima. O que a pesquisa sobre legitimidade tem a dizer sobre isso?

De um lado, tem havido um esforço intelectual para entender tais processos com o instrumental disponível. Veja-se, por exemplo, o estudo de Norris e Inglehart (2019), que vai usar a teoria do pós-materialismo e da cidadania crítica para explicar o fenômeno do populismo. Para os autores, por trás de fenômenos como Trump, Brexit e a extrema direita na Europa, haveria um "cultural backlash" aos avanços das democracias. Os autores analisam a emergência de um backlash conservador e, consequentemente, um reflexo autoritário estimulado pela ascensão dos valores culturais liberais (valores pósmaterialistas), o que constitui uma forte reação defensiva dos grupos conservadores que se sentiram ameaçados pelo rápido processo de mudança econômica, social e cultural. As condições econômicas e o crescimento na diversidade social aceleraram a reação, sendo que o backlash conservador contribui para o apoio aos partidos e líderes populistas e autoritários.

Por outro lado, no esforço de compreensão da ascensão do autoritarismo e do populismo, faltou a Norris e Inglehart (2019) uma autocrítica do diagnóstico otimista que emergia a partir de conceitos como "cidadãos críticos" e "pós-materialistas". De fato, os dados sobre o declínio da confiança nas instituições políticas já estavam presentes nesses diagnósticos, os quais não eram vistos como uma possível ameaça à legitimidade democrática, por não serem compreendidos como elementos do próprio fundamento da legitimidade em um sentido difuso. Uma outra chave analítica poderia aventar que tal descrédito nas instituições de representação política já poderia servir de base para apontar indícios aos apelos dos governos populistas autoritários, marcados pelo caráter antiestablishment, questionando assim o poder das autoridades e instituições do Estado.

Nesse sentido, Mounk (2019) aponta que já faz algum tempo que os cientistas políticos estão conscientes acerca do declínio da confiança nas instituições democráticas e da negatividade nas avaliações dos políticos. Entretanto, o autor considera que esses 
cientistas destinaram pouca atenção a esses fatos e que a perspectiva desenvolvida por estudiosos como Inglehart, Norris e Dalton torna-se menos plausível, pois é difícil considerar que pessoas comuns se voltem de forma tão radical contra os governos, sem criticar ainda mais o próprio sistema ${ }^{17}$.

Mas qual mecanismo tem operado para promover essa alteração repentina no "humor democrático"? Norris, Inglehart e a tradição de estudos da cidadania crítica indicam a reversão de expectativas criada especialmente pelos efeitos da crise econômica global pós-2008, que propiciou uma espécie de pós-materialismo às avessas. Trata-se de uma explicação importante, mas limitada. Os fenômenos políticos que estão balançando os alicerces das democracias, mesmo em países de sólida tradição democrática como EUA e Inglaterra, colocam uma interrogação sobre a natureza do compromisso com a democracia do "cidadão crítico".

Acreditamos que a resposta para essa questão e o avanço na compreensão da natureza dos vínculos entre cidadãos e democracia implicam incorporar novas perspectivas teóricas e instrumentos metodológicos. Alguns estudos mencionados acima parecem fornecer algumas pistas. Os estudos de Svolik, ao usarem desenhos experimentais, mostraram que tais vínculos, mesmo em democracias consolidadas, tendem a ser mais frágeis do que imaginamos. Quando os valores na sociedade se tornam polarizados, a situação tende a piorar! Nesses contextos, as pessoas abrem mão facilmente dos seus princípios democráticos desde que seja para vencer a facção oponente.

O estudo de Claassen (2020), por outro lado, nos mostra como se estabelece a dinâmica da opinião pública em relação à democracia e quais eventos ajudam a romper os compromissos com ela. Surpreendentemente, suas descobertas indicam que são os avanços na própria democracia que diminuem o seu apoio no eleitorado. Assim, a democracia não criaria sua própria demanda. Pelo contrário, avanços nas instituições, especialmente em sua dimensão inclusiva, provocariam reações de parcela do eleitorado. Nesse caso, mais do que criar sua própria demanda, o avanço da democracia parece elevar as exigências sobre o eleitor, especialmente em termos de tolerância.

A abordagem da legitimidade democrática como produto das visões e avaliações da democracia (Ferrín e Kriesi, 2016), por sua vez, destaca a dependência dessas avaliações dos resultados sociais e econômicos do sistema político (Torcal e Trechsel, 2016), trazendo à tona a necessidade de articulação entre a agenda de pesquisas sobre apoio político e a relativa a políticas públicas, o que ainda é incipiente.

Enfim, a conjuntura de crise da democracia coloca a necessidade de uma redefinição da agenda de pesquisas sobre legitimidade, de modo que a ciência política tenha condições de dar algumas respostas aos desafios do presente!

\footnotetext{
17 "Por um lado, é difícil imaginar que pessoas comuns possam se voltar de forma tão radical contra governos particulares - e assumir uma visão tão negativa do funcionamento diário de suas instituições - sem criticar ainda mais o próprio sistema. Por outro, a evidência de que a democracia está sob ataque só faz crescer" (Mounk, 2019, p. 130).
} 


\section{Referências bibliográficas}

Almond, G. A.; Verba, S. The civic culture: political attitudes and democracy in five nations. Boston: Little \& Brown, 1963.

Booth, J. A.; Seligson, M. A. The legitimacy puzzle in Latin America. Cambridge: Cambridge University Press, 2009.

BorbA, J.; CARDoso, G. R. "Os estudos de comportamento político na ciência política brasileira: caracterização do campo, apontamentos sobre a literatura e trabalhos de referência". BIB, n 89 , p. 1-33, 2019.

CANACHE, D. "Citizens' conceptualizations of democracy: structural complexity, substantive content, and political significance". Comparative Political Studies, vol. 45, no 9, p. 1.132-1.158, 2012.

CARLIN, R. E. "Distrusting democrats and political participation in new democracies: lessons from Chile". Political Research Quarterly, vol. 64, no 3, p. 668-687, 2011.

no 2, p. 399-422, 2018.

. "Sorting out support for democracy: a Q-method study". Political Psychology, vol. 39,

CARLin, R. E.; Moseley, M. "Good democrats, bad targets: democratic values and clientelistic vote buying". Journal of Politics, vol. 77, no 1, p. 14-26, 2015.

CARLIN, R. E.; Singer, M. M. "Support for polyarchy in the Americas". Comparative Political Studies, vol. 44 , no 11 , p. 1.500-1.526, 2011.

CARLIN, R.; LOVE, G.; Singer, M. M. A decade of democratic legitimacy in the Americas. In: Zechmeister, E. J. (ed.). The political culture of democracy in the Americas, 2014: democratic governance across 10 years of the AmericasBarometer. Nashville, TN: Latin American Public Opinion Project and Usaid, p. 193-226, 2014.

CASAleCchi, G. A. Legado democrático e apoio à democracia na América Latina: evidências e mecanismos explicativos. Curitiba: UFPR, 2018.

ClaAssen, C. "Estimating smooth country-year panels of public opinion". Political Analysis, vol. 27, no 1, p. 1-20, 2019.

. "In the mood for democracy? Democratic support as thermostatic opinion". American Political Science Review, p. 36-53, 2020.

COLLIER, D.; LEVITSKY, S. "Democracy with adjectives: conceptual innovation in comparative research". World Politics, vol. 49, no 3, p. 430-451, 1997.

Converse, P. E. The nature of belief systems in mass publics. In: APTER, D. E. (ed.). Ideology and discontent. Ann Arbor: University of Michigan Press, 1964.

Dahlum, S.; KNUtSEn, C. H. "Democracy by demand? Reinvestigating the effect of self-expression values on political regime type". British Journal of Political Science, vol. 47, no 2, p. 437-461, 2016.

DALTON, R. J. Democratic challenges, democratic choices. New York: Oxford University Press, 2004. "Citizenship norms and the expansion of political participation". Political Studies, vol. 56, no 1, p. 76-98, 2008.

2012. . The apartisan American: dealignment and electoral change. Washington, DC: CQ Press, 
LEGITIMIDADE DEMOCRÁTICA E APOIO POLÍTICO: INOVAÇÕES RECENTES NO DEBATE INTERNACIONAL

DALTON, R. Citizen politics: public opinion and political parties in advanced industrial democracies. $7^{a}$ ed. Washington: Congressional Quarterly Press, 2019.

Dalton, R.; KLINGemann, H. D. Citizens and political behavior. In: Dalton, R.; KLingemann, H.-D. (orgs.). The Oxford handbook of political behavior. Nova York: Oxford University Press, 2007.

Dalton, R.; Welzel, C. The civic culture transformed. New York: Cambridge University Press, 2014.

DE JONGE, C. P. K. "Should researchers abandon questions about 'democracy'?". Public Opinion Quarterly, vol. 80, no 3, p. 694-716, 2016.

Diamond, L.; Plattner, M. Democracy in decline? Baltimore: Johns Hopkins University Press, 2015.

EASTON, D. A systems analysis of political life. New York: John Wiley \& Sons, 1965.

"A re-assessment of the concept of political support". British Journal of Political Science, vol. 5, no 4, p. 435-457, 1975.

ECKSTEIN, H. A theory of stable democracy. Princeton: Princeton University Press, 1966.

ERIKSON, R. S.; MACKuen, M. B.; Stimson, J. A. The macro polity. New York: Cambridge University Press, 2002.

EuRoPeAn Social SuRVEY. ESS6-2012 Edition 2.4, round 6, December 2018. Disponível em: <http://www.europeansocialsurvey.org/>. Acesso em: jun. 2021.

FERRÍN, M.; KRIESI, H. Introduction: Democracy - The European verdict. In: FERRÍN, M.; KRIESI, H. (orgs.). How Europeans view and evaluate democracy. New York: Oxford University Press, 2016.

FISHER, J. (org.). The Routledge handbook of elections, voting behavior and public opinion. London: Routledge, 2018.

FOA, R. S.; MounK, Y. "The danger of deconsolidation: the democratic disconnect". Journal of Democracy, vol. 27, no 3, p. 5-17, 2016.

Fuks, M.; CASAlECCHI, G. A.; Ribeiro, E. A. "Determinantes contextuais da coesão do sistema de crenças democrático: evidências a partir da América Latina". Revista Brasileira de Ciência Política, no 28, p. 7-32, 2019.

FUKS, M., et al. "Qualificando a adesão à democracia: quão democráticos são os democratas brasileiros?". Revista Brasileira de Ciência Política, nº 19, p. 199-219, 2016.

GIBSON, J. L. "Intolerance and political repression in the United States: a half century after McCarthyism". American Journal of Political Science, vol. 52, nº 1, p. 96-108, 2008.

Gómez, B.; Palacios, I. Citizens' evaluations of European democracies. In: FerRín, M.; KRIESI, H. (orgs.). How Europeans view and evaluate democracy. New York: Oxford University Press, 2016.

Graham, M. H.; Svolik, M. W. "Democracy in America? Partisanship, polarization, and the robustness of support for democracy in the United States". American Political Science Review, vol. 114, n 2, p. 392-409, 2020.

HurRelmann, A.; SCHneider, S.; Steffek, J. Legitimacy in an age of global politics. London: Palgrave Macmillan UK, 2007.

INGLEHART, R. The silent revolution. Princeton: Princeton University Press, 1977.

Inglehart, R.; Welzel, C. Modernização, mudança cultural e democracia. São Paulo: Francis, 2009. 
JULIAN BORBA; GABRIELA RIBEIRO CARDOSO

Johnson, J. "Problemas conceituais como obstáculos ao progresso em ciência política. Quatro décadas de pesquisa em cultura política". Teoria \& Sociedade, no 12, 2004.

KRIESI, H.; MORLINO, L. Conclusion - What we have learnt, and where do we go from here? In: FERRÍN, M.; KRIESI, H. (orgs.). How Europeans view and evaluate democracy. New York: Oxford University Press, 2016.

LeVITSKY, S.; ZiblatT, D. Como as democracias morrem. Rio de Janeiro: Zahar, 2018.

LINZ, J. The breakdown of democratic regimes: crisis, breakdown and reequilibration. Baltimore: Johns Hopkins University Press, 1978.

LIPSET, S. M. "Some social requisites of democracy: economic development and political legitimacy". American Political Science Review, vol. 53, no 1, p. 69-105, 1959.

MAgalhães, P. Regime support. In: FISHeR, J. (ed.). The Routledge handbook of elections, voting behavior and public opinion. London: Routledge, 2018.

MoIsÉS, A. Os brasileiros e a democracia. São Paulo: Ática, 1995.

Mounk, Y. O povo contra a democracia. São Paulo: Companhia das Letras, 2019.

NORRIS, P. Critical citizens: global support for democratic government. Oxford, UK: Oxford University Press, 1999.

. Digital divide? Civic engagement, information poverty and the internet worldwide.

Cambridge: Cambridge University Press, 2001.

Press, 2002.

Democratic Phoenix: reinventing political activism. New York: Cambridge University

Democratic deficit: critical citizens revisited. New York: Cambridge University Press,

2011.

Making democratic governance work: how regimes shape prosperity, welfare and peace. New York: Cambridge University Press, 2012.

NorRis, P.; Inglehart, R. Cultural backlash. Cambridge: Cambridge University Press, 2019.

O'DonnelL, G. "Democracia delegativa?". Novos Estudos Cebrap, n 31, out. 1991.

PNUD. La democracia en América Latina: hacia una democracia de ciudadanas y ciudadanos. Buenos Aires: Alfaguara, 2004.

PRZEWORSKI, A. Democracia e mercado: reformas políticas e econômicas no Leste Europeu e na América Latina. Rio de Janeiro: Relume Dumará, 1994.

Recabarren, L.; Maldonado, G. "Objections to democracy: non-democratic citizens in Latin America". Documentos de Trabajo DT 04/2010, Instituto de Iberoamérica, Universidad de Salamanca, 2010.

RenNó, L., et al. Legitimidade e qualidade da democracia no Brasil: uma visão da cidadania. São Paulo: Intermeios, 2011.

Runciman, D. Como a democracia chega ao fim. São Paulo: Todavia, 2018.

SCHedler, A.; SARSFIELD, R. "Democrats with adjectives: linking direct and indirect measures of democratic support". European Journal of Political Research, vol. 46, no 5, p. 637-659, 2007.

Seligson, M. A.; CARrión, J. F. "Political support, political skepticism, and political stability in new 
LEGITIMIDADE DEMOCRÁTICA E APOIO POLÍTICO: INOVAÇÕES RECENTES NO DEBATE INTERNACIONAL

democracies". Comparative Political Studies, vol. 35, no 1, p. 58-82, fev. 2002.

SHORE, J. The welfare state and the democratic citizen: how social policies shape political equality. Switzerland: Palgrave Studies in European Political Sociology, 2019.

SorokA, S. N.; Whezien, C. Degrees of democracy: politics, public opinion, and policy. Cambridge: Cambridge University Press, 2010.

Svolik, M. W. "Which democracies will last? Coups, incumbent takeovers, and the dynamic of democratic consolidation". British Journal of Political Science, vol. 45, no 4, p. 715-738, 2014.

2, pp. 1-21, 2019.

"Polarização versus democracia". In: Journal of Democracy (em português), vol. 8, no

. "When polarization trumps civic virtue: partisan conflict and the subversion of

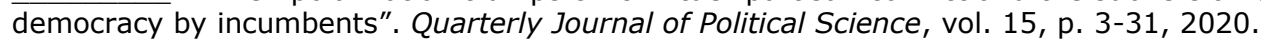

Torcal, M.; Moncagatta, P. Political support. In: Badie, B.; Berg-Schlosser, D.; Morlino, L. (orgs.). International encyclopedia of political science. Los Angeles: Sage, 2011.

TORCAL, M.; TRECHSEL, A. H. Explaining citizens' evaluations of democracy. In: FerRín, M.; KRIESI, H. (orgs.). How Europeans view and evaluate democracy. New York: Oxford University Press, 2016.

VeIGA, L. F., et al. "El efecto de la experiencia democrática en la estructura de la legitimidad en América Latina y el Caribe". Opinião Pública, vol. 23, no 2, p. 289-315, 2017.

WeßELS, B. Determinants of democratic legitimacy: concepts, measures, outcomes. In: FerRÍn, M.; KRIESI, H. (orgs.). How Europeans view and evaluate democracy. New York: Oxford University Press, 2016.

WeStLE, B. Political beliefs and attitudes: legitimacy in public opinion research. In: HURRELMANN, A.; SCHNEIDER, S.; STEFFEK, J. (orgs.). Legitimacy in an age of global politics. London: Palgrave Macmillan UK, 2007.

WLEZIEN, C. "The public as thermostat: dynamics of preferences for spending". American Journal of Political Science, vol. 39, no 4, p. 981-1.000, 1995.

\begin{abstract}
Democratic legitimacy and political support: recent innovations in the international debate Recent phenomena related to the so-called crisis of democracies, such as populism and political polarization, have posed new challenges to research on legitimacy and political support. Faced with the recognized limits of the estonian model, since the 1990s, several authors have proposed new analytical perspectives to studies on the phenomenon. In this article, we present and analyze, in addition to David Easton's original conception, five recent perspectives that have brought relevant innovations to studies on political support. In the final part, the advances and limits of this literature for the understanding of some dilemmas of contemporary democracies are discussed, especially the growing support of the electorate in various countries of the world for candidates and parties with authoritarian political platforms.
\end{abstract}

Keywords: political culture; legitimacy; political support; democracy

\title{
Resumen
}

Legitimidad democrática y apoyo político: innovaciones recientes en el debate internacional Los fenómenos recientes relacionados con la llamada crisis de las democracias, como el populismo y la polarización política, han planteado nuevos desafíos a la investigación sobre la 
legitimidad y el apoyo político. Frente a los límites reconocidos del modelo estonio, desde la década de 1990, varios autores han propuesto nuevas perspectivas analíticas a los estudios sobre el fenómeno. En este artículo, presentamos y analizamos, además de la concepción original de David Easton, cinco perspectivas recientes que han aportado innovaciones relevantes a los estudios sobre apoyo político. En la parte final, se discuten los avances y límites de esta literatura para comprender algunos dilemas de las democracias contemporáneas, especialmente el creciente apoyo del electorado en varios países del mundo para candidatos y partidos con plataformas políticas autoritarias.

Palabras clave: cultura política; legitimidad; apoyo político; democracia

\section{Résumé}

Légitimité démocratique et soutien politique: innovations récentes dans le débat international Les phénomènes récents liés à la soi-disant crise des démocraties, tels que le populisme et la polarisation politique, ont posé de nouveaux défis à la recherche sur la légitimité et le soutien politique. Face aux limites reconnues du modèle estonian, depuis les années 1990, plusieurs auteurs ont proposé de nouvelles perspectives analytiques aux études sur le phénomène. Dans cet article, nous présentons et analysons, en plus de la conception originale de David Easton, cinq perspectives récentes qui ont apporté des innovations pertinentes aux études sur le soutien politique. Dans la dernière partie, les avancées et les limites de cette littérature pour la compréhension de certains dilemmes des démocraties contemporaines sont discutées, en particulier le soutien croissant de l'électorat dans divers pays du monde pour les candidats et les partis avec des plateformes politiques autoritaires.

Mots-clés: culture politique; légitimité; soutien politique; démocratie

Artigo submetido à publicação em 9 de junho de 2020. Versão final aprovada em 5 de fevereiro de 2021.

Opinião Pública adota a licença Creative Commons CC-BY. 